
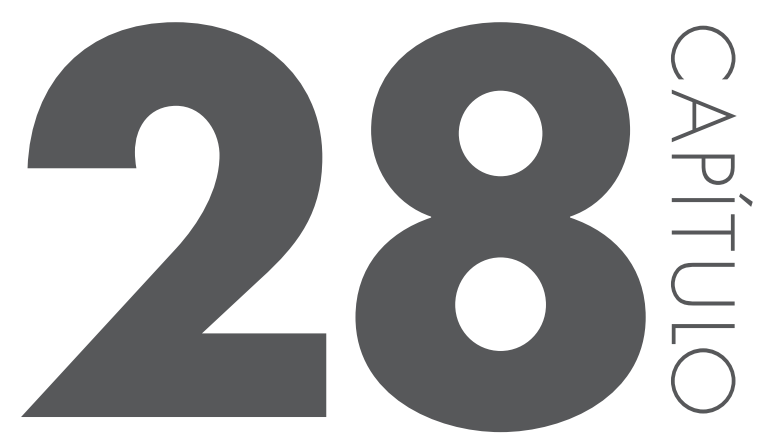

\title{
MULHERES NA IGREJA CATÓLICA: PERSISTÊNCIA HISTÓRICA DO PATRIARCADO
}

Tavares, Marli José '; Costa, Carmem Lúcia ${ }^{2}$

1 Mestranda do Programa de Pós-Graduação em Geografia RC/UFG

2 Docente do Programa de Pós-Graduação em Geografia RC/UFG

* email: marlitavares15@gmail.com

\section{RESUMO}

O presente estudo pretende compreender como se constituiu o papel das mulheres na Igreja Católica, desde a igreja primitiva até o movimento da Teologia da Libertação, a partir das relações de gênero e através do patriarcado, que se institucionalizou na sociedade humana alcançando as religiões. As análises mostram que o enfrentamento feminino à ação do patriarcado ocorre de maneira mais discreta onde a Igreja Católica tem uma presença maior, ao passo que, onde o poder da Igreja é mais contestado e enfrentado, muda também a atuação feminina, A territorialização feminina na Igreja se constitui no elo entre Igreja e sociedade, sendo que a mulher continua destinada ao cuidar. Mesmo 
em constante contato com a realidade social, ela não tem uma participação nas decisões. A distância entre apresentar a realidade e apontar intervenções, ainda é grande. Assim, o presente estudo busca conhecer, minimamente, o papel feminino na religião, aqui em específico, o cristianismo católico.

Palauras-chave: Mulher; Cristianismo; Patriarcado 


\section{INTRODUC̣ÃO}

Historicamente, o homem se constituiu como dominador, seja na sua relação com a natureza e/ou em relação ao sexo feminino. Teologicamente, diversos textos bíblicos dão base para a subserviência feminina, e são utilizados sem o devido cuidado em decorrência do contexto que foram produzidos. Assim, o presente estudo pretende conhecer, minimamente, o papel feminino na religião, aqui em específico, o cristianismo católico.

Somente após diversas conquistas seculares das mulheres, foi que as religiões começaram a repensar o papel feminino, haja vista que toda coerção, cedo ou tarde acaba por irromper. Nesse contexto, desvendar a situação feminina dentro das religiões é algo complexo, os relatos existentes foram realizados por homens, por isso a análise deve ser cautelosa, certamente há omissões, e distorções.

Em se tratando do cristianismo, o documento mais antigo é a bíblia, e como todos sabem esta foi escrita por homens. Estudiosa do tema, Elizabeth S. Fiorenza (1995), é uma autora recorrente neste estudo. Segundo a autora, no cristianismo primitivo, observa-se um movimento de inclusão dos segmentos sociais marginalizados pelos judeus, incluindo, a mulher:

[...] no movimento de Jesus, portanto, as mulheres podiam tornar-se discípulas, embora fossem socialmente marginais, religiosamente inferiores e quase sempre pessoas imundas do ponto de vista do culto. Jesus questionava radicalmente as relações sociais, hierárquico-religiosas e patriarcais. A autoridade de Jesus anula categoricamente qualquer relação de domínio dentro da comunidade cristã (Mt 23, 7-12) [...] Jesus rejeitou radicalmente todas as relações de dependência e dominação. Essa exigência de estruturas inclusivas e livres de domínio, no movimento de Jesus, oferece a base teológica para o reconhecimento das mulheres como discípulas de pleno direito. (FIORENZA, 1995, p. 196).

Liderar missões cristãs, profetizar e apostolar fez parte do papel da mulher, isto aconteceu nos tempos de Jesus, pois nas tradições cristãs primitivas, o que prevaleceu foi o poder dos padres, portanto o modelo patriarcal e androcêntrico.

Após a morte de Jesus, Fiorenza (1995) aponta que há um "silêncio lucano" em relação à participação feminina nas primeiras comunidades cristãs. A visibilidade feminina está justamente na ocultação dos relatos, às reuniões cristãs aconteciam nas casas, o que foi denominado de igrejas domésticas. O 
que para Johnson (1995) é bem provável que elas, também, evangelizavam, além é claro de preparar o local para as reuniões.

A relação da mulher com o cristianismo é contraditória e emblemática, e se acentua ao longo do tempo. O cristianismo se firma, sendo liderado por homens, a mulher aparece como uma 'peça' do processo, que recorrentemente é associada a figuras e personagens que atendessem ao contexto do momento, como a associação à Maria, mãe de Jesus, exemplo de mãe, associada a ações divinas que se confundem com os processos de geração, alimentação, cuidado, clemência e misericórdia. “[...] Invocada mãe por excelência, Mãe de Deus, Mãe de Misericórdia, Mãe do Consolo Divino, Nossa Mãe ”. (JOHSON, 1995, p. 55).

Durante a alta Idade Média, a mulher foi duramente massacrada, certamente, foi o período de maior discriminação. $O$ pensamento clerical, fundamentado nos 'santos padres', foi marcado pela misoginia. A mulher foi associada à figura de Eva, que corrompe e instiga a maldade. "[...] Foi pela mulher que começou o pecado, por sua culpa todos morremos". (COYLE, 1999, p. 120).

A veneração à Maria era a repulsa ao corpo e à exposição da mulher ao público, à mulher era reservado o espaço privado, o doméstico, à reclusão. À Igreja era-lhes reservado apenas o direito da oração, negando-lhe o direito a pregar e governar. Mulheres como Maria Madalena e Joana D arc não eram exemplos a serem seguidos. (FIORENZA, 1995).

O poder da sociedade medieval estava nas mãos da Igreja Católica, com suas ordens religiosas, regras e normas, sempre excludentes e rígidas. $\mathrm{O}$ que dizer então da inquisição? Período de exacerbação da perseguição à figura feminina e à heresia de bruxaria. Muraro (2000), em sua análise do Malleus Maleficarum, (Martelo das bruxas) o famoso manual de diagnóstico das bruxas publicado no século XV, aponta que a inquisição foi uma tentativa da Igreja Católica manter-se no poder, diante do desenvolvimento da sociedade burguesa, que se fortalecia na crise econômica e política que desestruturava o sistema feudal.

Ou seja, a sociedade passava por uma transição social: o mercantilismo, formação dos Estados Nacionais, restauração do Direito Romano. E a Igreja Católica, com sua rigidez, estava abalada, a inquisição foi uma tentativa de afirmação e restabelecimento do poder, este essencialmente masculino. Freire e Sobrinho (2006) buscam compreender o porquê das mulheres serem o principal alvo da inquisição

Embora seja difícil recuperar traços de resistência por parte da mulher, devido ao silêncio que envolve todo esse fenômeno, poder-se-ia supor que a busca, pela mulher, de outras formas de conhecimento causou todo o ódio masculino. O que fez ser 
castigada por toda sua atuação e considerados 'bruxarias'. Toda essa repressão contra a mulher está contida, manifestada na obra de Malleus Maleficarum [...] (FREIRE.e SOBRINHO, 2006, p. 54).

A partir da análise do contexto do período, apreende-se que a caça às bruxas se deu por medo das mudanças que estavam ocorrendo, a mulher representava, naquele momento, a própria sociedade, que estava buscando uma nova maneira de organização social, contrária ao desejo da Igreja que era de manter a velha forma.

É interessante pensar que, mais uma vez, as repressões vêm acompanhadas e respaldadas por figuras e personagens femininos que justificasse a posição da Igreja em coibir a atuação da mulher na sociedade. Eva, personagem bíblica que leva o homem ao pecado, é constantemente recorrida, estigmatizando a mulher e incitando o ódio.

Isto posto, pode-se afirmar que a resistência se fazia de ambos os lados, pois a Igreja resistia em reconhecer a mulher, enquanto sujeito social. Uma herança do patriarcado, ou seja, uma sociedade humana guiada por homens, tornando a mulher em um ser inferior. Assim, a ação feminina se faz nas brechas. Destinadas ao espaço privado, é nele que as mulheres se manifestam e buscam o conhecimento do mundo. Fazer o parto, cuidar da criança, do idoso, certamente instigou a mulher na busca por saberes medicinais. Uma afronta aos homens, visto que a eles cabiam o conhecimento científico, como a medicina, por exemplo.

A inquisição foi à expressão mais cruel de condenar e massacrar a mulher, assim, Muraro (2000), aponta que mais de 100 mil mulheres foram queimadas vivas. Mas, a Igreja não foi a única instituição de repressão na Idade Média, as classes 'superiores', como os intelectuais e humanistas, também contribuíram para a inferiorização da mulher.

Vale ressaltar que nem mesmo as transformações advindas dos novos ideais da Idade Moderna instigou a liberdade feminina, o que se percebe são novas maneiras de repressão. A Igreja Católica continua com a mesma visão de submissão da mulher. O Concílio de Trento (1545-1563) reafirma a reclusão feminina, os trabalhos das religiosas deveriam ser feitos em conventos e não nas ruas em contato com a sociedade.

Este mesmo contexto estava presente no Brasil, onde a participação das mulheres na Igreja, não foi diferente. Mesmo tendo um catolicismo 'popular' ${ }^{1}$ sua atuação estava reservada à participação aos cuidados da Igreja, ou se reclusar em conventos e casas de recolhimentos. É importante ressaltar que essas 'casas' recolhiam as mulheres, sem a obrigatoriedade dos votos (AZZI, 1994). Não 
seria esta, uma maneira de controlar o comportamento das mulheres que não seguiam a vida religiosa? Assim, regulamentavam o casamento e sufocava a rebeldia feminina, mantendo-as submissa.

Todavia, no final do século XIX, é possível visualizar uma inovação no papel da mulher na Igreja Católica e sua atuação no trabalho e na cidade. Muitas congregações religiosas foram surgindo no Brasil, certamente, um dos fatores que contribuiu para tal crescimento, foi o abandono do Império e depois do Estado para com a classe mais pobres. Essas congregações atuavam na catequese, na imprensa, nas missões, na educação e na ação social.

A Santa Sé ${ }^{2}$ reconheceu que era preciso rever o papel da mulher diante do novo contexto:

[...] a importância global da ação capilar por elas exercidas em todos os domínios do apostolado, mas também a necessidade de adaptar o antigo direito das religiosas, baseado numa reclusão muito rígida, às condições inteiramente novas da sociedade do século XIX [...] (AUBERT, 1975, p. 113).

Sem dúvida, as congregações femininas permitiram certo reconhecimento do papel da mulher na sociedade humana, porém é notável que a atuação da mulher nada mais era do que a extensão do privado, ou seja, a atuação na área da saúde e da educação era a continuidade do trabalho doméstico, não havendo, portanto um rompimento com a concepção andocêntrica.

Durante todo século XIX as congregações femininas se espalharam pelo Brasil e no início do século XX chega à cidade de Catalão (GO). Nesse contexto, Paim (1995) informa que em 1921, as Irmãs Agostinianas Missionárias, fundaram o Colégio Nossa Senhora Mãe de Deus, que até os dias atuais é dirigido por Elas. O referido Colégio, com seu modelo de educação rígida e com especial controle disciplinar, formava jovens mulheres com ênfase no aspecto doutrinário e sacramental, ou seja, diferente do modelo de catolicismo aqui predominante, que era o 'popular'. Catalão $(\mathrm{GO})$ participou da importação de idéias e comportamentos religiosos europeus, o que pode ser constatado com a instalação do Colégio Nossa Senhora Mãe de Deus para atender ao apelo das famílias mais abastadas, preocupadas com a formação de suas filhas, como ressalta Paim“[...] as famílias Fayad, Safatle, Sebba, se empenharam para trazer as madres agostinianas da Espanha [...]" (PAIM 1995, p. 7).

O Brasil sempre foi um receptor da cultura europeia, na religião não foi diferente. Desde o Império estreitou suas ligações com Roma, isso se deve ao processo de Romanização ${ }^{3}$, que é um exemplo claro da negação da realidade 
brasileira e uma valorização do modelo europeu, especialmente da Igreja de Roma. Assim, o Brasil se dinamizava, as cidades cresciam e queriam seguir o progresso a qualquer custo, as transformações do século XIX juntamente com as consequências da exploração do capitalismo atingiram toda a sociedade, em meio a tudo isso estava a mulher e sua ação. Qual seria então o papel da mulher nessa sociedade moderna, urbana, mas com traços fortemente rurais?

A mulher continuava a ocupar um lugar distinto do homem; enquanto este tinha livre acesso ao espaço público e privado, a mulher estava restrita à vida privada. Porém, a sociedade brasileira, nas primeiras décadas do século XX, exigia mais dinamização do gênero feminino, o que não significa uma mudança de comportamento; e sim a participação feminina no espaço público com as mesmas características da função da mulher no espaço privado. Uma vez que, o espaço público era restrito, dimensionado para a participação da mulher na sociedade.

Dessa maneira, a educação sistematizada não deveria mais estar tão distante das mulheres. Certamente, ser professora era a profissão que aparentemente não confrontava com o casamento e com os 'deveres femininos'. Segundo Louro (2000), aos poucos as mulheres brasileiras se inseriam no meio letrado, que antes estava, prioritariamente, reservado aos homens:

[...] as escolas normais se enchem de moças. A princípio são algumas, depois muitas, por fim os cursos normais tornam-se escolas de mulheres. Seus currículos, suas normas, os uniformes, o prédio, os corredores, os quadros, as mestras e mestres, tudo se faz desse um espaço destinado a transformar meninas/mulheres em professoras [...] (LOURO, 2000, p. 454)

A inserção da mulher na vida ativa da sociedade acontecia sem grandes rupturas, mesmo porque a sociedade brasileira, como demonstrada, também seguia o modelo patriarcal. $\mathrm{O}$ homem era figura central, tudo girava em torno do masculino. A economia, a política e a religião eram administradas pelos homens. Este modelo refletia até mesmo no planejamento das cidades, que segregava e ainda segrega a mulher. Como aponta Rosa Tello (2009):

[...] sin embargo, para las políticas urbanas el espacio cotidiano, como las mujeres, es invisible, porque, al ser 'a privacion de lo privado', es decir, al ser continuación del espacio doméstico, 'es como si no existiera [...] (TELLO; RINCÓN, 2009, p. 47). 
A cultura ocidental não reconhece a especificidade dos gêneros, e até o espaço urbano reflete a homogeneização e a segregação. A cidade é pensada a partir de um planejamento urbano normatizador, racional, vinculado ao masculino.

A maneira que a mulher encontrou para ser atuante na sociedade, na primeira metade do século XX, em uma cidade do interior de Goiás, foi à extensão do privado, ou seja, através da educação, saúde e obras sociais.

Educação e religião são aliadas para a 'preparação' da nova mulher exigida pelo progresso. Percebe-se que o papel da mulher não foi repensado e sim moldado ao atual contexto, que não trazia novas concepções, mas sim uma restauração do modelo preexistente.

A Igreja Católica sabia que era preciso seguir a nova sociedade, mas de maneira a restaurar e não renovar, como ressalta Azzi (1994, p. 22) "[...] Em outras palavras, restaurar é restabelecer em perfeita forma o modelo antigo [...]”. Para a Igreja, seguir ao progresso era colocar as pessoas na prática sacramental: batizar, confessar e casar.

Especificamente no Estado de Goiás, o Catolicismo de caráter popular e devocional era e ainda é presente. Como exemplo se têm a realização de festas em louvores a santos, como a Festa em Louvor a Nossa Senhora do Rosário, realizada em Catalão, sendo área de pesquisa do estudo em questão. Para a Igreja Católica, o catolicismo popular apresentava uma ameaça ao modelo romanista.

Em 1943, um grupo de franciscanos veio dos Estados Unidos, atendendo ao convite de D. Emanuel Gomes de Oliveira, Arcebispo de Goiás, para desenvolver apostolado junto às populações Goianas. O trabalho desenvolvido pelos franciscanos teve a colaboração das professoras, recém-formadas no Colégio Nossa Senhora Mãe de Deus. (WISE, 1989).

A primeira comunidade franciscana foi estabelecida, em Anápolis, no ano de 1944, com os Freis Paulo, Jaime e Damião. (WISE, 1989). No mesmo ano, para a Paróquia de Catalão, vieram Frei João Francisco Granahan - como superior e vigário, e Freis Cristóvão e Gabriel.

Os franciscanos deram às normalistas do Colégio Nossa Senhora Mãe de Deus a oportunidade de prática da formação profissional e religiosa que receberam, pois a formação como normalista, não era apenas uma preocupação com o letramento, mas também e tão importante quanto, estava à evangelização através da catequese, que foi, a arma mais poderosa usada pela Igreja para a expansão de seus princípios, pela busca de novos fiéis, e pelo controle do papel da mulher na sociedade.

Igreja e Estado estavam juntos no processo de 'letramento', mesmo o Estado sendo laico, desde a instituição da República. Nota-se também que a mulher 
foi um eixo fundamental nesta parceria, pois atuava nos dois comandos sem maiores questionamentos, cumprindo seu dever de trabalhadora cristã católica, contribuindo, dessa maneira, para o desenvolvimento da sociedade humana, pois a normalista atendia os espaços deixados à parte pelo Estado e pela religião. A professora atuava na educação (letramento) e ainda levava os princípios morais e religiosos para a sociedade.

A normalista, em Catalão, exercia o ofício de educadora pela fé, sua preocupação era com a disseminação do catolicismo romano, a partir da educação. Toda essa preocupação e dedicação se fizeram pelo fato de Catalão apresentar, naquele período, um forte catolicismo popular. Não somente em Catalão, mas Goiás como todo. Wyse (1989), ao descrever o contexto no qual os franciscanos foram convidados a virem para Goiás, salienta a pouca participação da Igreja principalmente no interior Goiano.

O Brasil desenvolveu um catolicismo próprio, oriundo do contato que os jesuítas e colonos estabeleceram com os índios. Chauí (2001) aponta que a religiosidade popular no Brasil atingiu de forma distinta o meio rural e o meio urbano. O catolicismo rural apresentava uma herança do padroado, uma noção de cristandade pautada na relação de confiança e troca, essas relações ganhavam força com a ausência dos representantes oficiais da Igreja.

Todo esse contexto incentivou os leigos ao desenvolvimento religioso de suas comunidades, por intermédio da formação de irmandades, festas em louvor a santos e romarias. Catalão, mesmo como referência de desenvolvimento urbano no início do século XX, como aponta Palacín (1994), apresentava fortes traços de um catolicismo popular rural.

A Igreja interviu, colocando a mulher como intermediária do processo. Educar implica em ensinar conceitos e detalhá-los, e a religião é uma maneira de difundir e estipular regras a serem seguidas, podendo até entrar no campo científico, nutricional, filosófico, e, sobretudo, comportamental, dependendo da religião. Por isso existem escolas religiosas Judaicas, Católicas, Islâmicas, entre outras agremiações religiosas, para que as crianças desde tenra idade possam inculcar os preceitos da religião e viver segundo os mesmos.

Uma sociedade se constitui a partir das regras que são impostas aos indivíduos, condicionando seus comportamentos, que podem ser concordantes ao modelo estabelecido, ou contrários a ele. Mesmo porque, são a partir das regras, que se escolhem os comportamentos a serem seguidos.

Vale ressaltar que religião e educação se interligam, basicamente, pelo fato de unirem esforços em torno da ética, da moral e da disciplina. Valores esses que absorvidos pelo indivíduo e dão a sociedade um estereótipo mais homogêneo, que é o que interessa à religião e a sociedade. Mas as coerções geram resistências 
e estas se apresentam dentro do contexto coercitivo, assim as mulheres mudam comportamentos agindo através do que estão condicionadas.

No decorrer do século XX, a Igreja Católica preocupa-se mais com as questões sociais, em especial a América Latina, que sempre teve maior contingente católico. Wise (1994) destaca que no Brasil a Igreja passou por grandes transformações desde que o catolicismo deixou de ser a religião oficial, com o advento da Proclamação da República em 1889, decorrente ainda de movimentos messiânicos, falta de sacerdotes e o crescimento de outras religiões, contribuíram para a restauração (como já mencionando). Assim, há um envolvimento maior por parte da Igreja Católica com o cotidiano de seus fiéis, estando mais presentes aos seus problemas econômicos e sociais. Foi neste contexto que surgiu a 'Teologia da Libertação', um movimento pastoral que envolve os membros da Igreja com as questões sociais. Este movimento tem grande participação feminina, dando sequência a novas perspectivas à mulher no contexto da Igreja.

\section{A TEOLOGIA DA LIBERTAC̄ÃO E AS NOVAS PERSPECTIVAS EM RELAC̣ÃO À MULHER E A IGREJA CATÓLICA}

A sociedade humana se constitui através do movimento dos sujeitos que a compõem, e as transformações acontecem a partir dos questionamentos e resistências ao que está estabelecido, seja na economia, cultura, política e/ou religião. Assim, a relação mulher e Igreja Católica ganhau nova moldagem a partir de meados do século XX, certamente com influência do movimento feminista e da Teologia da Libertação.

A gênese da Teologia da Libertação está no fervoroso ano de 1950, quando as teorias marxistas, com ênfase na redistribuição de riquezas, invadiram a América do Sul com seus milhares de pobres relegados à exclusão e sofrimento. Como o discurso da Igreja Católica sempre foi de apoio aos menos favorecidos, e uma Teologia tem suas raízes na religião, a Teologia da Libertação se caracterizou no Catolicismo Romano, mas seus ideais, ao longo do tempo, alcançaram outras religiões.

O termo Teologia da Libertação foi criado pelo teólogo peruano Gustavo Gutiérrez, em 1971, e sua centralidade está no pobre. No Brasil o expoente desta teologia é Genézio Darci Boff, mais conhecido pelo pseudônimo Leonardo Boff (2009). Assim, é Boff (2009) que o estudo recorre para se conhecer o cerne da Teologia da Libertação 
[...] o punctum stantis et cadentis da Teologia da Libertação é o pobre concreto, suas opressões, a degradação de suas vidas e os padecimentos sem conta que sofre. Sem o pobre e o oprimido não há Teologia da Libertação. Toda opressão clama por uma libertação. [...]A Teologia da Libertação partiu diretamente dos pobres materiais, das classes oprimidas, dos povos desprezados como os indígenas, negros marginalizados, mulheres submetidas ao machismo, das religiões difamadas e outros portadores de estigmas sociais.(BOFF, $2011 \mathrm{n} / \mathrm{p}^{4}$ )

O caminho para a superação das desigualdades está respaldado na Teologia da Libertação, por uma nova forma de interpretação dos textos bíblicos. E a mulher se insere neste contexto, a Teologia da Libertação abre um espaço para maior participação feminina, através de sua participação nas Comunidades Eclesiais de Base (CEB`s) ${ }^{5}$. No momento em que surge as mulheres são convidadas a assumirem atividades eclesiais. A leitura da Bíblia é confrontada com os problemas do cotidiano, a celebração coordenada por mulheres, em lugar da missa. O que para Azzi (1977) é uma relativa autonomia.

O avanço não está apenas no âmbito da religião, a prática libertadora desperta e aguça o olhar para a mulher, atingindo outras áreas da sociedade, inclusive o meio científico. Trabalhos voltados para o papel da mulher na religião tornaram-se concretos a partir de pesquisas realizadas por teólogas da libertação, em busca do reconhecimento da ação feminina desde as comunidades primitivas. O que permitiu indagações sobre o que estava exposto até o momento, apresentando uma nova visão da participação feminina que é integradora e construtora da realidade cristã e social.

A Teologia da Libertação foi um novo caminho para que as mulheres buscassem um espaço menos discrepante na Igreja em relação aos homens, e por consequência trouxe também mais visibilidade de suas ações sociais. A participação nas Comunidades Eclesiais de Base possibilitou um resgate histórico e outras interpretações bíblicas, o que foi um grande avanço para as reflexões teológicas feministas. Os reflexos desta interpretação crítica atingem a sociedade até os dias atuais. Estudos como este, são possíveis a partir de teólogas da linha do feminismo de libertação.

É importante ressaltar que, mesmo com maior ação e liderança feminina nas comunidades, há muito que transformar para o reconhecimento efetivo do

${ }^{4} \mathrm{http}: / /$ leonardoboff.wordpress.com/2011/08/09/quarenta-anos-da-teologia-da-libertacao

${ }^{5}$ São comunidades com objetivo de aproximar a lgreja à realidade dos fiéis, através da hermenêuticabuscam a interpretação da bíblia associada à realidade do momento. Surgiu com o respaldo do Concílio do Vaticano II (1962 a 1965), com apoio da Teologia da Libertação e das Conferências católicas de Medellin (1968) e Puebla (1979). Não por coincidência a ênfase aos pobres e exclúidos foi o caráter principal das Conferencias, pois a América Latina vivia as consequências das ditaduras, da repressão e do abandono políitco e social. As CEB`s possibilitou maior aproximação do povo às propostas de melhorias sociais e políticas. AZZl, Riolando. A Igreja Católica no Brasil no período de 1950 a 1975. Religião e Sociedade, n² 2, nov. Rio de Janeiro : ISER, 1977. 
papel da mulher, pois mesmo sendo explícita sua participação, infelizmente seu discipulado ainda não é reconhecido pela hierarquia clerical.

As transformações na Igreja, desencadeadas a partir de 1950, foram significantes em relação à mulher, todavia, é necessário salientar que a participação feminina na Igreja e na sociedade sempre existiu de maneira incisiva, Gebara (1990) chama atenção, que estas transformações trouxeram a maior possibilidade de se conhecer a realidade da mulher na história:

[...] a emergência das mulheres nas sociedades e na Igreja não significa a entrada delas na história. Elas sempre estiveram presentes. Trata-se da irrupção de uma nova consciência das causas históricas da marginalização feminina, uma nova consciência que nasce de práticas concretas, leva a uma ação transformadora e a uma mudança na compreensão do ser mulher (GEBARA, 1990, p. 12).

Dessa maneira, à medida que as mulheres cristãs adentraram os movimentos sociais contra a pobreza e a favor da luta por melhores condições de vida, elas também tiveram aproximação dos movimentos feministas, que possibilitaram maior conhecimento das questões de gênero:

Os ganhos foram inegáveis, todavia, fica claro que a Igreja Católica continua mantendo a mulher fora dos espaços de decisão, sendo este destinado ao homem, reafirmando assim o patriarcado.

$\mathrm{Na}$ religião, a submissão feminina é menos questionada, o clero, da Igreja Católica, que surgiu ainda na Idade Média, continua formado apenas por homens. E é no alto clero que surgem as decisões que direcionam o comportamento de homens e mulheres na Igreja Católica. Dessa maneira, afirma-se que na Igreja, a atuação feminina ainda é predominante nos bastidores, ou seja está associada papel doméstico o que reforça a reprodução de um modelo de dominação masculina, a dominação dos ou padres.

\section{CONSIDERAC̣ÕES FINAIS}

As relações de gênero, sempre estiveram presentes na sociedade humana, mas com significações diferentes de acordo com o contexto histórico, e é assim que a humanidade caminha, circunstancialmente pelas ações sociais, econômicas, religiosas e culturais, formando, assim, o espaço vivido. Sendo este ocupado por sujeitos que fazem parte do movimento social e das diversas dimensões que ocupam dentro de uma ordem estabelecida. 
As análises mostram que o enfrentamento feminino à ação do patriarcado ocorre de maneira mais discreta onde a Igreja Católica tem uma presença maior, ao passo que onde o poder da Igreja é mais contestado e enfrentado, muda também a atuação feminina, A territorialização feminina na Igreja se constitui no elo entre Igreja e sociedade, sendo que a mulher continua destinada ao cuidar. Mesmo em constante contato com a realidade social, ela não tem uma participação nas decisões. A distância entre apresentar a realidade e apontar intervenções, ainda é grande. 


\section{WOMEN IN CATHOLIC CHURCH: historical persistence of patriarchy}

\section{Abstract}

This study wants to understand how constituted the role of women in the Catholic Church, since the primitive church until the movement of liberation theology, from gender relations and through the patriarchy, which was institutionalized in society, reaching the religions. The analyzes show that women confront to the patriarchy inaction occurs in a more discreet manner, where the catholic church has a greater presence, while, where the power of the Church is more challenged and confronted, changes the female engagement, the female in the territorial Church constitutes the link between church and society, wherein the woman continues on caring. Even in constant contact with a social reality, she does not have a participation in the decisions. The distance between to show the reality and to point interventions is still substantial.

Keywords: Women. Christianity. Patriarchate 


\section{REFERÊNCIAS}

AUBERT, R. A Igreja o Liberalismo e o Mundo Moderno. Petrópolis: Vozes:, 1975. (Coleção Nova História da Igreja. Volume V. Tomo 1).

AZZl, R. A Igreja Católica no Brasil no período de 1950 a 1975. In: Religião e Sociedade, n² 2, nov. Rio de Janeiro: ISER, 1977.

BOURDIEU, P. A Dominação Masculina. Tradução de Maria Helena Kühner. $7^{0}$ ed. Rio de Janeiro: Bertrand Brasil, 2010.

CAMPOS, M. das D. Catalão: estudo histórico e geográfico. Goiânia: Tipografia e Editora Bandeirante, 1976. CHAUÍ, M. 0 que é ideologia? São Paulo: Brasiliense, 2001.

COYLE, K. Maria Na Tradição Cristã. a partir de uma perspectiva contemporânea. Tradução de Bárbara T. Lambert. São Paulo: Paulus, 1999. (Colecção Teologia Sistemática).

DEL PRIORI, M. (Org.). História das Mulheres do Brasil. São Paulo: Contexto. 2000.

ENGELS, F. A origem da família, da propriedade privada e do Estado. São Paulo: Centauro, 2002. FIORENZA, E. S. Discipulado de Iguais. uma eklesialogia feminista crítica da libertação. Tradução de Yolanda S. Toledo. Petrópolis: Vozes, 1995.

As origens cristãs a partir da mulher: uma nova hermenêutica. Tradução de João Rezende Costa. São Paulo: Paulinas, 1992.

FOUCAULT, M. A governabilidade. In: Microfísica do Poder. 18 ed. São Paulo: Graal, 1979. p. 277-293.

FREIRE, M. S.; SOBRINHO, V. P. A figura feminina no contexto da inquisição. In: Educere et Educare. Cascavel: Unioeste, 2006. Vol. I $n^{0} 1$ jan/jun. 2006. P. 53 a 58.

GEBARA, I. A mulher faz teologia. In: BINGEMER, M. C. et. al. 0 rosto feminino da teologia. Aparecida do Norte: Santuário, 1990.

JOHNSON, E. A. Aquela que É. 0 mistério de Deus no trabalho teológico feminino. Tradução de Atilio Brunetta. Petrópolis, Vozes. 1995.

LOPES, M.. J. M. et all (Org.) Gênero e saúde. Porto Alegre: Artes Médicas, 1996.

LOURO, G.; DEL PRIORI, M. (Org.). História das mulheres no Brasil. São Paulo: Contexto, 2000.

MURARO, R.. M.. Textos da fogueira. Brasilia: Letrativa, 2000.

SAFFIOTI, H. B. Gênero, patriarcado, violência. São Paulo: Editora Fundação Perseu Abramo, 2004.

SCOTT, J. Gênero: uma categoria útil para análise histórica. Tradução de Christine Rufino Dabat e Maria Betânia Ávila. 2002, (do original) Joan Scott - Gender: a useful category of historical analyses. Gender and the politics of history. New York, Columbia University Press. 1989. In: www.dhnet.org.br/textos/generodh/gencategoria. html. Acesso em março de 2014.

TELLO, R.; RINCÓN, S. P. Inclusión y exclusión de las mujeres em las políticas y prácticas de renovación urbana. In: TELLO- QUIRÓZ. Ciudad y diferencia. Barcelona: Edicions Bellaterra, 2009.

WYSE, A. 0. F. M. No Coração do Brasil, Custódia do Santíssimo Nome de Jesus em Goiás. Anápolis: Editora, 1989. 